\title{
Management of a Complicated Crown Fracture in a Tertiary Care Hospital
}

\author{
Md Abdul Hannan Sheikh ${ }^{1}$, Fahd A A Karim ${ }^{2}$, Sultana Parveen ${ }^{3}$ \\ Received: September 10, 2016 Accepted: December 10, 2016 \\ doi: http://dx.doi.org/10.3329/jemc.v7i1.30749
}

\begin{abstract}
Restoration of a fractured tooth is routinely performed in clinical practice. Many factors are considered in an effort to provide optimal mechanical properties, aesthetics, longevity as well as patient acceptance. In this type of challenging endeavour, main effort should be made to save as much of the coronal tooth structure to increase survival rate of endodontically-treated teeth. This case report presents a 35-year-old male with an oblique complicated crown fracture of maxillary left central incisor tooth. The procedure used to repair the fracture was gingivectomy followed by endodontic treatment. The root canal was filled with a root canal sealer and gutta-percha points. After root canal obturation, the tooth was restored with a glass fiber post and composite resin without additional crown coverage. The restoration made it possible to maintain the remaining tooth structure in a good occlusion and resulted in a high level of patient satisfaction.
\end{abstract}

Key words: Complicated crown fracture; Endodontic treatment; Glass fiber post; Composite resin restoration

J Enam Med Col 2017; 7(1): 35-38

\section{Introduction}

Aesthetic rehabilitation of crown fractures of the maxillary anterior teeth is one of the greatest challenges to the dental specialist. ${ }^{1}$ The type and location of fracture depends upon age of the patient, amount of force and direction of blow, but an in vitro study concluded that most of the traumatized incisors fracture in an oblique fashion from the labial to lingual aspects with the fracture line proceeding in an apical direction. ${ }^{2,3}$ Oblique coronal fractures that involve pulp and extend apically into the root (subgingival) may also invade the critical area of biologic width. These fractures are particularly challenging.

Several factors influence the management of coronal tooth fractures, including extent of fracture, pattern of fracture and restorability of fractured teeth, secondary trauma, presence or absence of fractured tooth fragment, occlusion, aesthetic, finances and prognosis. $^{4-6}$
With the recent improvements in the dental materials, resin-based restorative materials with the use of tooth colored fiber-reinforced polymer posts are of choice because of several advantages such as aesthetics, bonding to tooth structure, low modulus of elasticity similar to that of dentin. ${ }^{7}$ This case report presents a case of complicated crown fracture managed by glass fiber post and composite resin.

\section{Case report}

A 35-year-old male patient reported to the dental unit of Enam Medical College Hospital, Savar, Dhaka with the complaint of mild pain and broken tooth on the maxillary anterior region. He had a history of trauma on that area one week back due to an accident. On extraoral examination no abnormalities were detected, intraoral examination revealed an oblique coronal fracture of maxillary left central incisor with involvement of pulp (Fig 1). The fracture line extended a little below the gingival level at the palatal surface of the tooth. Intra-

1. Classified Specialist in Conservative Dentistry \& Endodontics, Combined Military Hospital, Savar Cantonment, Savar, Dhaka

2. Assistant Professor, Update Dental College \& Hospital, Dhaka

3. Specialist in Conservative Dentistry \& Endodontics, Dhaka

Correspondence Md Abdul Hannan Sheikh, Email: drhannan65@gmail.com 
oral periapical radiograph revealed an intact periodontal ligament space with no root or alveolar bone fracture. The case was diagnosed as complicated crown fracture of maxillary left central incisor. After considering the above conditions, endodontic treatment followed by restoration with glass fiber post and direct composite crown buildup was planned.

\section{Treatment procedure}

With consent of the patient, local anesthesia was administered and gingivectomy was done to expose the line of fracture palatally and hemostasis was achieved. Then a straight line endodontic access cavity was made and pulpal remnants were removed. The working length was determined by working length measuring radiograph. Then the root canal was prepared as standardized technique at 18 $\mathrm{mm}$ working length up to $60 \mathrm{~K}$ file and obturated with gutta-percha point by lateral condensation technique (Fig 2).

On the next appointment, the gutta-percha point was partially removed from the root canal using peeso reamer until it measured the estimated depth required for the post, leaving $5 \mathrm{~mm}$ of filling material at the apex to maintain a good seal (Fig 3). The glass ionomer luting cement (GC corporation) was applied with a lentulospiral into the post space and the glass fiber post (GLASSIX-1.35 mm diameter) was inserted into the canal (Fig 4). Excess cement was removed with a clean instrument.

Then the shade was selected, the tooth was isolated with cotton roll and air dried. Uniform layer of $7^{\text {th }}$ generation self-etch adhesive bonding (beauty bond) was applied according to manufacturer's instruction. The adhesive layer was dried with gentle air blast for five seconds and light curing was done for 10 seconds. Then the crown was built up incrementally with Giomer (beautifil II-\# A2). Each increment was light cured for 20 seconds. Then the tooth was finished and polished and occlusion was checked (Fig 5).

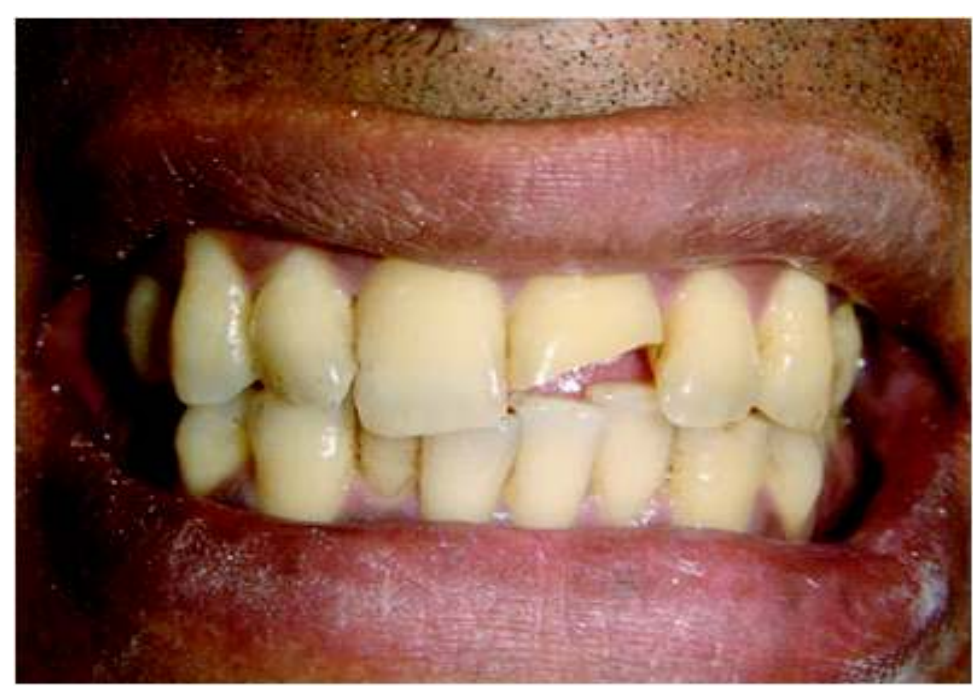

Fig 1. Initial photograph showing oblique coronal fracture

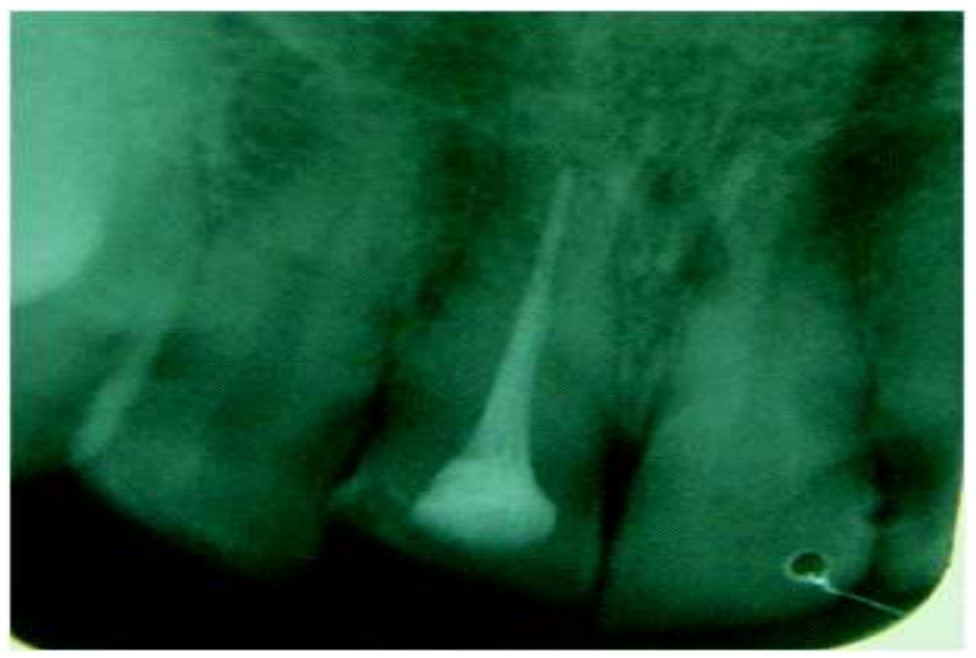

Fig 2. After root canal obturation

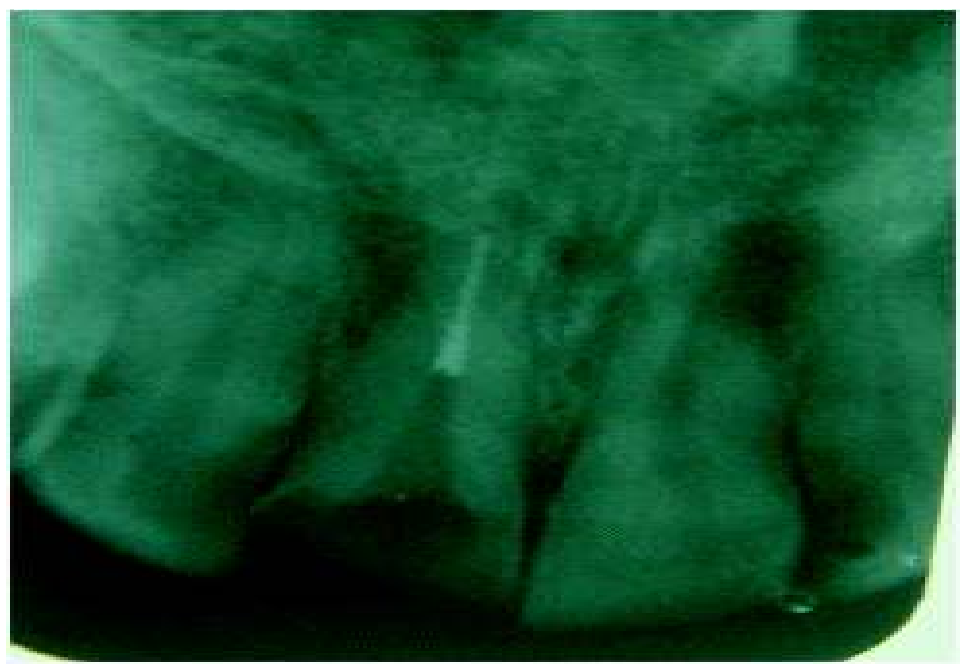

Fig 3. Remaining gutta-percha after partial removing 


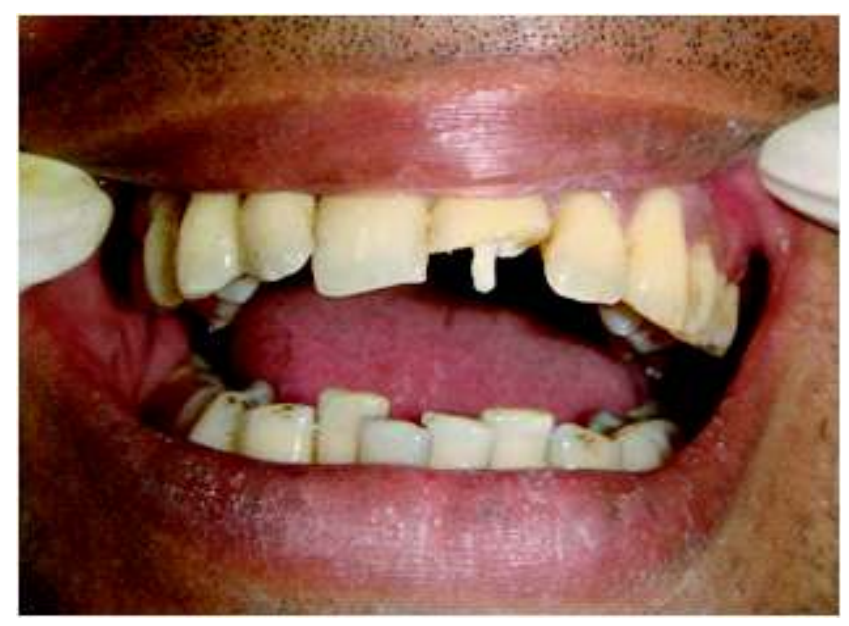

Fig 4. Placement of Glassix post

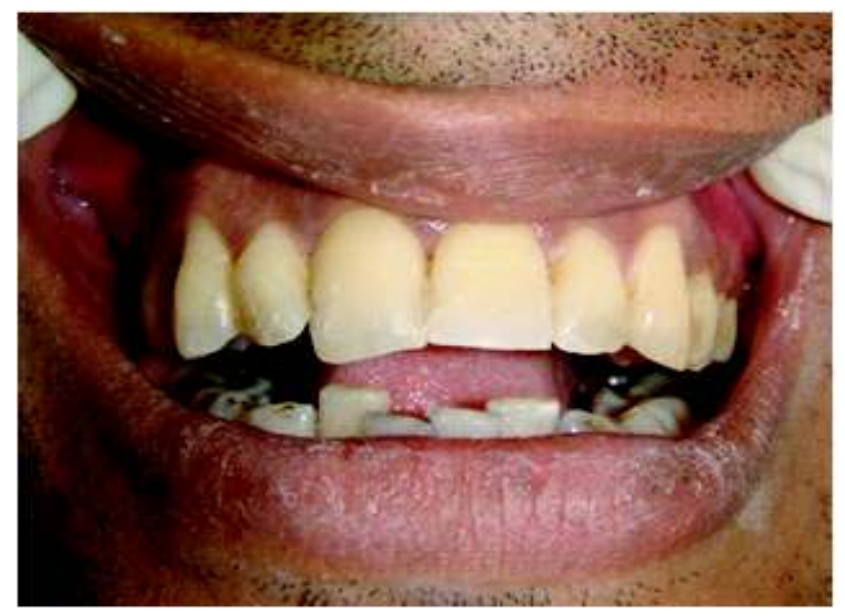

Fig 5. Final photograph after build-up

\section{Discussion}

Fracture of the tooth below the gingival attachment presents restorative problems due to difficulty of access. ${ }^{8}$ In such cases, orthodontic or surgical exposure of the fracture is necessary to facilitate further treatment. Surgical exposure of the fracture margin can be achieved by gingivectomy with or without osteotomy. This technique is simple and allows restoration to be completed soon after injury. However, surgical exposure in aesthetic regions has unacceptable results and is best used only for the palatal surface of anterior teeth. ${ }^{9,10}$ In the case presented here, the fragment margin was exposed by gingivectomy. This technique allowed sufficient exposure and further orthodontic or surgical extrusion was not deemed necessary.

The treatment options for this type of cases include reattachment (if fracture fragment is available), post- supported direct composite build-up, prosthetic restoration or tooth extraction followed by rehabilitation. ${ }^{11}$ In the presented case the patient was unable to retrieve the fracture fragment, so restoration with glass fiber post and direct composite crown buildup was planned. This technique has some major advantages: it eliminates the need for sacrificing any tooth structure, less time-consuming, more economic and cheaper than indirect restorations that have additional laboratory cost.

The selection of post is important because it may have an influence on the longevity of the tooth. Multiple factors may influence post selection. These include amount of remaining coronal tooth structure, tooth anatomy, position of the tooth in the arch, root length, root width, canal configuration, stress, post design, post material, bonding ability, core retention and aesthetics. ${ }^{12}$ In this case, GLASSIX post $(1.35 \mathrm{~mm}$ diameter) was used. It is cylindrical in shape with a gentle rounded cone ideal for the root canal and exactly matched by the calibrated reamers.

The length of the post ideally should be at least as long as the clinical crown, providing $4-5 \mathrm{~mm}$ of gutta-percha apical seal. The diameter of the post should be minimal and not more than one-third of the root diameter. ${ }^{13}$ Techniques for removing gutta-percha includes solvents, thermal and mechanical removal. Solvents are best avoided as they have the potential to damage the root canal filling material that remains. The thermal method of removing gutta-percha using heat pluggers is safer but more time-consuming. Mechanical removal of gutta-percha point using Gates-Glidden drill or peeso reamer is efficient and probably is the most commonly used technique, but it is associated with a higher risk of root perforation if carried out incorrectly. ${ }^{14}$ To avoid this problem, in this case, peeso reamers were used on slow speed with continuous up and down motion along with cooling arrangement. The method used to place the cement into the canal before placement of post has a significant effect on post retention. Lentulospiral was used in this case to fill the canal with the cement which has been shown to be the most effective method for cement placement.

Although some researchers believed in the past that posts could improve the fracture resistance in endodontically-treated tooth, nowadays it is known that preparation of a post space may increase the chances of root fracture ${ }^{15}$, so posts should only be used when other options are not available to retain a core. ${ }^{16}$ Studies were 
performed comparing the fracture resistance of endodontically-treated teeth when they were restored with or without posts. According to Grandini et al ${ }^{17}$ fiber posts associated to direct resin restorations is a faster therapeutic option that conserves remaining tooth structure. The authors evaluated fiber post/direct resin restoration longevity by $6,12,24$ and 30 -month recall and satisfactory results were found although any comparison with teeth without posts had not been made. ${ }^{17}$ In this case, restoration was done with glass fiber post and direct composite crown build-up.

Improvements in composites and the development of dentine bonding systems have stimulated a trend toward more conservative techniques of tooth restoration, which afford increased opportunities to preserve badly-broken permanent incisor teeth. ${ }^{18}$ Currently used glass fiber post systems are designed to be corrosion resistant, are able to bond to tooth structure, are aesthetically pleasing, and allow retrieval when the post core system fails. ${ }^{19}$

Recently, concepts of adhesive dentistry have been applied to the field of endodontics with a specific focus on obtaining a "MONOBLOCK" in which the core material, sealing agent and the root canal dentine form a single cohesive unit. Based on this monoblock concept, some new obturating materials have come up in the market which include Activ GP (Cone + Sealer), Realseal (Cone + Sealer), Filtek P90 (silorane based composite), Ketac N100 (nRMGIC). ${ }^{20}$

It is not possible to guarantee in every case. However, managment of a fractured tooth by glass fiber post and composite resin is a simple conservative approach to provide aesthetics and functional rehabilitation. Periodic follow-up examinations and radiographs are essential to monitor the restoration of teeth with complicated crown fracture.

\section{References}

1. Attila IO, Cenk MHA, Sendra MT. Multidisciplinary approach to the rehabilitation of a crown-root fracture for immediate esthetics. Dent Traumatol 2006; 22: 48-52.

2. Andersen JO. Etiology and pathogenesis of traumatic dental injuries: a clinical study of 1298 cases. Scand J Dent Res 1970; 78: 329.

3. Stokes A, Hood J. Impact fracture characteristic of intact and crowned human central incisors. J Oral Rehabil 1993; 20: 89-95.

4. Olsbarg S, Jacoby T, Krejci I. Crown fracture in the permanent dentition: pulpal and restorative consideration. Dent Traumatol 2002; 18(3): 103-115.
5. Reis A, Francci C, Loguercio AD, de Assis TG, Crivelli DD, Oda $\mathrm{M}$ et al. Re-attachment of anterior fractured teeth: fracture strength using different techniques. Oper Dent 2001; 26(3): 287-294.

6. Andersen FM, Noren JG, Andersen JO, Engelhardtsen S, Lindgh-Stromberg U. Long term survival of fragment bonding in the treatment of fractured crowns. Quintessence Int 1995; 26: 669-681.

7. Caputo AA, Standlee JP. Pins \& posts-why, when \& how. Dent Clin North Am 1976; 20: 229-311.

8. Turgut MD, Gonul N, Altay N. Multiple complicated crownroot fracture of a permanent incisor. Dent Traumatol 2004; 20: 288-292.

9. Andreasen JO, Andreasen FM, Andersson L. Crown-root fractures. In: Textbook and color atlas of traumatic injuries to the teeth. $4^{\text {th }}$ edn. Copenhagen: Blackwell Munksgaard, 2007: 314-336.

10. Emerich-Poplatek K, Sawicki L, Bodal M, AdamowiczKlepalska B. Forced eruption after crown/root fracture crown. Dent Traumatol 2005; 21: 165-169.

11. Torvi SJ, Kala M. Restore the natural - a review and case series report on restorement. J Clin Exp Dent 2004; 6(5): e595-e598.

12. Goldman M, De Vitre R, Tenca JL. A fresh look at posts \& cores in multirooted teeth. Compend Contin Educ Dent 1984; 5(9): 711-715.

13. McComb D. Restoration of the endodontically treated tooth. Dispatch 2008; 2: 1-18.

14. Ricketts D, Tait CM, Higgins AJ. Tooth preparation for postretained restorations. British Dental Journal 2005; 198: 463-471.

15. Gohring TN, Peters OA. Restoration of endodontically treated teeth without posts. Am J Dent 2003; 16(5): 313-317.

16. Assif D, Gorfil C. Biomechanical considerations in restoring endodontically treated teeth. J Prosthet Dent 1994; 71(6): $565-567$.

17. Grandini S, Goracci C, Tay Fr, Grandini R, Ferrari M. Clinical evaluation of the use of fiber posts and direct resin restorations for endodontically treated teeth. Int $\mathrm{J}$ Prosthodont 2005; 18(5): 399-404.

18. Combe EC, Shaglouf AMS, Wilson WHF. Mechanical properties of direct core build-up materials. Dent Mater 1999; 15: 158-165.

19. Newman MP, Yaman P, Dennison J, Rafter M, Billy E. Fracture resistance of endodontically treated teeth restored with composite posts. J Prosthet Dent 2003; 89: 360-367.

20. Arora V, Yadav MP, Sing SP, Arora P, Choudhary P. Effect of adhesive obturation and post obturation monoblock systems on reinforcement of peri-cervical dentin (PCD). Int $\mathrm{J}$ of British Trend and Technology 2015; 8(1): 1-5. 